\title{
RAZÃO DE BOWEN COMO DIRETRIZ DE PROJETO PARA ESPAÇOS LIVRES: PRAÇAS PÚBLICAS EM CIDADES DO OESTE PAULISTA, SP
}

\author{
Elaine Cristina Barboza ${ }^{1}$
}

\author{
Antônio Jaschke Machado
}

\begin{abstract}
RESUMO
Considerando projetar a paisagem urbana através da integração do espaço natural e construído, na busca empírica por indicadores reais de qualidade ambiental urbana e demais parâmetros para investigar a contribuição dos espaços livres visando seu incremento; apresenta-se uma contribuição metodológica ao desenvolvimento de projeto de espaços livres considerando a vegetação e o parâmetro micrometeorológico razão de Bowen $(\beta)$ e consequentes derivações de padrão urbanístico como ferramenta para desenho urbano e desenvolvimento sustentável. Exemplificado com a criação de uma praça segundo tais critérios e sua implantação no Distrito Industrial do município de Junqueirópolis (SP), região oeste do estado; este trabalho evidencia a necessidade de se criar espaços com cobertura heterogênea para maior variabilidade dos fluxos turbulentos, atenuando o aquecimento do ar para promoção do conforto térmico ao ambiente urbano.
\end{abstract}

PALAVRAS-CHAVE: Projeto Urbano. Razão de Bowen. Vegetação. Espaço livre.

\section{BOWEN RATIO AS GUIDELINES PROJECT FOR FREE SPACES: PUBLIC SQUARES IN CITIES WEST OF SÃO PAULO, SP}

\begin{abstract}
ABSTRATC
Considering designing the urban landscape through the integration of the countryside and built in the empirical search for real indicators of urban environmental quality and other parameters to investigate the contribution of the free spaces aiming its increase; it presents a methodological contribution to the development of open spaces project considering the vegetation and the micrometeorological parameter Bowen ratio $(\beta)$ and consequent pattern of urban derivations as a tool for urban design and sustainable development. Exemplified by the creation of a square according to these criteria and their implementation in the Industrial District the municipality of Junqueiropolis (SP), west of the state; this work highlights the need to create spaces with heterogeneous coverage for greater variability of turbulent flows, reducing air heating to promote thermal comfort to the urban environment.
\end{abstract}

KEY WORDS: Urban project. Bowen ratio. Vegetation. Free space.

\footnotetext{
${ }^{1}$ Graduação em Arquitetura e Urbanismo na Faculdade de Ciências e Tecnologia - UNESP, ec_barboza@hotmail.com.

${ }^{2}$ Professor Assistente Doutor do Departamento de Geografia na Faculdade de Ciências e Tecnologia - UNESP, jaschke.machado@gmail.com.
} 


\title{
CÓMO DISEÑAR DIRECTRICES BOWEN MOTIVO DE ESPACIOS LIBRES: PLAZAS PÚBLICAS EN CIUDADES DE OESTE SAO PAULO, SP
}

\begin{abstract}
RESUMEN
Teniendo en cuenta el diseño del paisaje urbano a través de la integración de las zonas rurales y construido en la búsqueda empírica de los indicadores reales de la calidad del medio ambiente urbano y otros parámetros para investigar la contribución de los espacios libres destinados a su aumento; presenta un aporte metodológico para el desarrollo de espacios abiertos proyecto considerando la vegetación y la relación de parámetros micrometeorológica Bowen ( $\beta$ ) y la consiguiente patrón de derivaciones urbanas como una herramienta para el diseño y desarrollo urbano sostenible. Ejemplificado por la creación de una plaza de acuerdo con estos criterios y su aplicación en el distrito industrial de la ciudad de Junqueiropolis (SP), la región occidental del estado; este trabajo pone de manifiesto la necesidad de crear espacios con cobertura heterogénea de una mayor variabilidad de los flujos turbulentos, la reducción de la calefacción de aire para promover la comodidad térmica al medio ambiente urbano.
\end{abstract}

PALABRAS CLAVE: Proyecto urbano. Cociente Bowen. Vegetación. Espacios libres.

\section{INTRODUÇÃO}

Uma revolução está em curso na qual a ecologia vem sendo paulatinamente subvertida pelos ditames do globalismo (BERNARDIN, 2015). Em termos de projeto de espaços livres esta subversão tem acarretado a aplicação, por parte de grande parcela dos profissionais envolvidos, de uma cartilha ambientalista simplista, incongruente e pouco ou quase nada realista. Este trabalho busca manifestar a necessidade da persistência na busca de um conhecimento científico empírico, de natureza complexa, o qual sirva de alicerce para um desenho urbano que de fato reproduza o mais próximo possível da realidade as diretrizes concebidas no projeto.

A busca pela aplicação dos princípios de desenho urbano orientados pela concepção arquitetural do bioclimatismo traduz-nos uma interação de vários elementos; climáticos, do lugar, de uma cultura, com a finalidade de criar ou recriar ambientes urbanos. Segundo Romero (2000), as concepções bioclimáticas podem ser aplicadas ao espaço urbano, de forma que os ambientes urbanos resultantes possam se transformar também em filtros dos elementos do clima adversos às condições de saúde e conforto térmico do 


\section{Periádica Eletrânica \\ Fórum Ambiental}

da Alta Paulista
Volume 11, Número 09, 2015

Produção e as

Tecnologias Sustentáveis

homem, de modo que todo o repertório do meio ambiente urbano (edifícios, vegetação, ruas, praças e mobiliário urbano) busque satisfazer às exigências do conforto térmico para as práticas sociais do homem.

Uma vez que a forma urbana surge através da ação humana, a composição da paisagem urbana se dá pela integração (entenda-se por ação de planejamento) do espaço natural e construído. Magnoli (2006), no entanto, coloca que o espaço livre, qualquer que seja, enquanto objeto de desenho só é relevante se analisado diante das atividades e necessidades do homem urbano; isso faz com que seja secundária a questão da quantidade de espaços livres tornando então, sua importância relativa à sua localização.

De maneira geral, são as superfícies edificadas/impermeabilizadas e vegetadas que compõe o sistema urbano (GRIMMOND and OKE, 1991). Imerso neste sistema existe um subsistema denominado sistema de espaços livres (MACEDO, 2012), o qual consiste em todo o conjunto de espaços livres urbanos de uso e propriedade pública, pelos quais perpassa o cotidiano da vida urbana. As feições paisagísticas das cidades do Oeste Paulista em uma primeira aproximação são caracterizadas pela dispersão das formas urbanas, marca peculiar do paisagismo contemporâneo brasileiro.

Este estudo teve início em cidades de pequeno e médio porte do Oeste Paulista (Presidente Prudente, Assis e lepê), caracterizadas por malha urbana ainda com contraste bastante marcante nos seus limites com a área rural, bastante evidente através de uma variação espacial abrupta do tipo de cobertura da superfície. Na porção interior da malha urbana estes contrastes de coberturas podem também ser evidenciados pela alternância existente entre ruas, quadras construídas e parques ou praças urbanas.

A avaliação da contribuição da vegetação nestes espaços considerou a análise de ocupação do entorno edificado, a qualidade e tipo de piso ou pavimentação empregada, a qualificação da vegetação disponível nestes locais e seu desempenho através do acompanhamento das trocas convectivas, aferições dos fluxos de calor e radiação solar incidente e equacionada para obtenção do balanço radiativo. Tal avaliação busca contribuir no desenvolvimento de estratégias para ocupação de áreas verdes na malha 
urbana e compreender demais aspectos relacionados aos indicadores ambientais e de habitabilidade urbana.

\section{OBJETIVOS}

Mediante interpretação do balanço de energia, aferido por meio de medições fixas da radiação incidente, temperatura do ar e umidade; traçou-se uma correlação entre espaços públicos com diferentes tipos e adensamento de vegetação e os valores da razão de Bowen $(\beta)$, estabelecendo-a como um critério para investigar a contribuição dos espaços livres para o incremento da qualidade ambiental urbana. O parâmetro micrometeorológico razão de Bowen ( $\beta$ ) constituiu-se como indicador de padrão urbanístico representado pelas praças e parques urbanos, parâmetro este diretamente relacionado às trocas convectivas entre as diferentes superfícies destas praças e a atmosfera urbana (BARBOZA E.C. e MACHADO. A. J., 2015).

Os estudos sobre a estimativa dos fluxos de calor em associação com a avaliação da distribuição da ocupação urbana tem demonstrado sua relevância para a compreensão do ambiente construído; sendo que a presença da vegetação ajuda a estabilizar os efeitos térmicos reduzindo extremos de temperatura se conduzida como instrumento de planejamento e desenho ambiental urbano.

Deste modo buscou-se despontar os estudos através de sua aplicação enquanto método de desenvolvimento de projeto para concepção de praças e parques urbanos, correlacionando-o com aspectos importantes da análise de paisagem, criação e abordagem paisagística e, ademais abordar questões de urbanismo sustentável e desenho urbano.

\section{MÉTODO DE ANÁLISE}

\subsection{Diagnóstico: Caracterização local e diretriz de intervenção}




\section{Periádica Eletrânica}

A média horaria de Bowen nas áreas investigadas por meio do estudo observacional resultou na distinção de cinco naturezas de composição espaço do urbano com valores característicos sintetizados no Quadro 1.

O parcelamento da terra por diferentes categorias de agrupamentos vegetais implica no modo como a superfície irá transferir parte da energia armazenada para o ar urbano adjacente. Esta transferência apresenta uma natureza turbulenta, tanto para o fluxo de calor sensível $\left(Q_{H}\right)$ como também para o fluxo de calor latente $\left(Q_{E}\right)$.

Nota-se uma tendência de elevação no valor de $\beta$ para as categorias C1 a C3, enquanto as categorias C4 e C5 apresentam um decréscimo no decorrer da tarde. Esta observação empírica constitui-se a principal diretriz para o projeto. Ou seja, praças com uma cobertura relativamente homogênea, mesmo quando constituídas por espaços verdes, apresentam um padrão diurno tradicional no qual o fluxo de calor sensível $\left(Q_{H}\right)$ aumenta em relação ao fluxo de calor latente $\left(Q_{E}\right)$, acompanhando o aquecimento diurno. Porém, praças mistas constituídas por uma cobertura bastante heterogênea, apresentam um padrão inverso no qual o fluxo $Q_{H}$ diminui em relação ao fluxo $Q_{E}$, arrefecendo o aquecimento diurno. A razão física por detrás desta constatação ainda tem sido motivo de investigação, mas, por enquanto, com clareza percebe-se que a turbulência atmosférica exerce um papel importante, dispersando o calor que se armazena sobre as superfícies. Quanto mais heterogênea a praça maior a variabilidade dos fluxos turbulentos, atenuando 0 aquecimento do ar sobrejacente às superfícies ensolaradas e evitando o estresse hídrico da vegetação. 
Quadro1: Agrupamento vegetal.

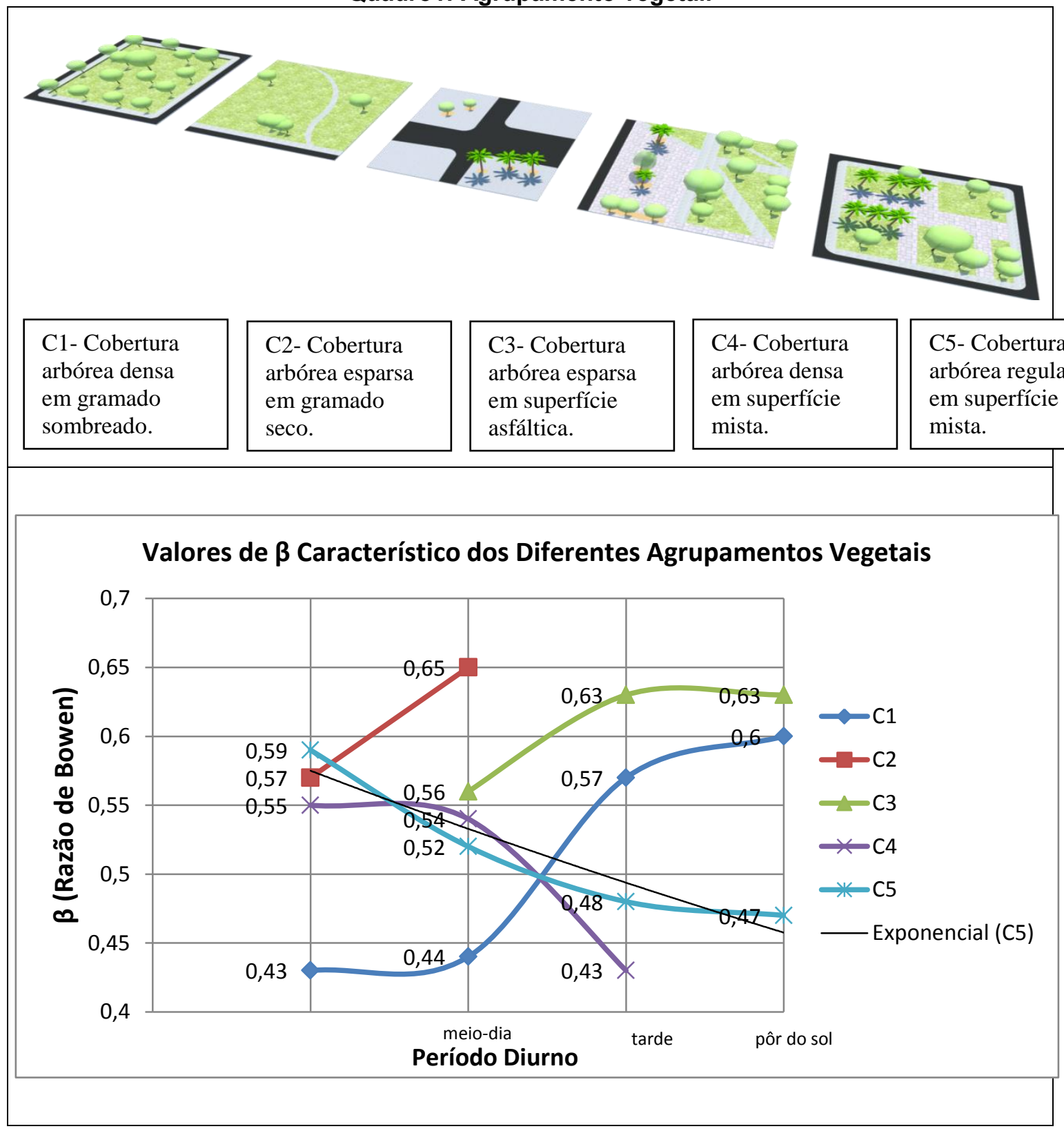

Fonte: AUTORES, 2015.

As regiões arborizadas mantiveram as taxas de $\beta$ oscilando abaixo de 0,5 mesmo após o ápice solar. Este valor trata-se de quando o fluxo $Q_{H}$ corresponde à metade do $Q_{E}$; valores de $\beta$ menores que meio, significam que $a$ entrada de calor na atmosfera se dá mais por calor latente, que não contribui para um aumento da temperatura na baixa atmosfera e sim, para um aumento da umidade (OKE, 1987). 


\section{Periódica Eletrânica}

Nos experimentos realizados evidenciamos também que a amplitude para os valores da radiação demostraram o efeito do sombreamento da copa das árvores de espécies diferentes, com características peculiares quanto ao tipo de copa, altura e características foliares. Do mesmo modo identificaram-se valores característicos para superfícies gramadas, pavimentadas e concretadas, e a natureza permeável ou não dos materiais empregados para cobertura do solo.

O estudo de caso que apresentamos a seguir manteve como diretriz a criação de uma área com características similares ao apresentado no Quadro 1: desenvolver uma implantação que privilegiasse o usuário e termicamente contivesse uma cobertura arbórea densa sobre superfície mista (C4).

No município de Junqueirópolis (SP), pertencente à região de Presidente Prudente (SP) no oeste do estado, possui grande extensão territorial, com uma população estimada em aproximados 20 mil habitantes, com economia baseada principalmente na prestação de serviços e em segundo lugar, na produção agropecuária (IBGE, 2015); iniciamos o trabalho para o desenvolvimento do projeto de intervenção com o levantamento e caracterização da área. Trata-se de uma área verde pertencente ao Distrito Industrial da cidade, localizada junto a marginal de acesso principal, tendo sido efetuado o plantio de diferentes de tipos mudas com crescimento rápido basicamente: Tecas (normalmente destinada a reflorestamento), um número relevante Ipês-brancos, e alguns exemplares frutíferos também remanescentes da implantação (Quadro 2). 
Quadro 2: Caracterização local.

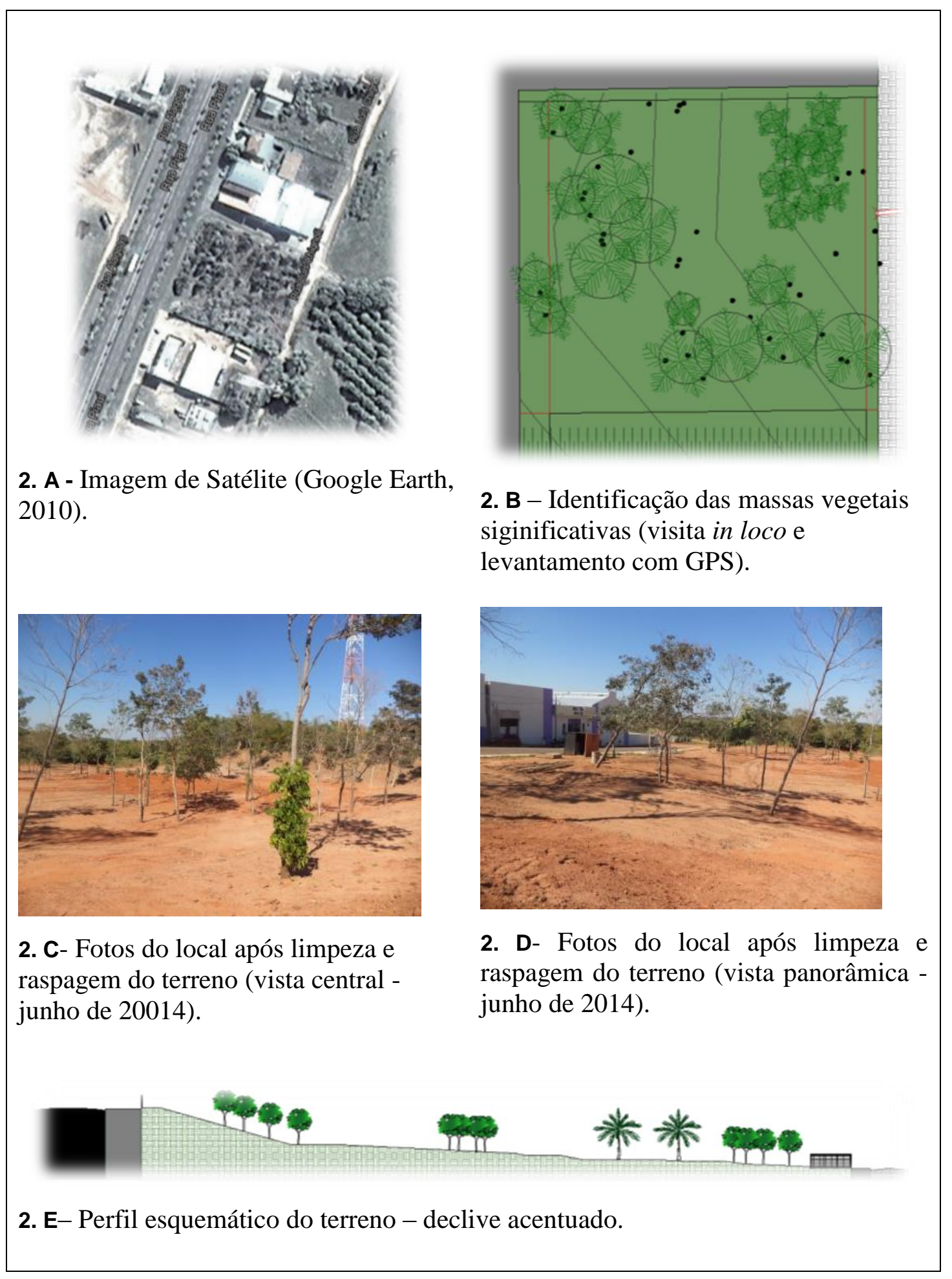

Fonte: AUTORES, 2015. 


\subsection{Projeto: Elaboração e Execução}

O projeto partiu de princípios básicos da concepção de espaço para o paisagismo: criação de lugares (espaço para encontro de pessoas ou o próprio encontro - contemplação) e relações de proporção e escala (harmonia entre os elementos que compõe o espaço). Como ferramentas de projeto, utilizou-se a criação de visuais e pontos focais, considerando a captura de paisagem como forma de ampliar virtualmente o local, mesmo diante da natureza muito íngreme do terreno e pontuando o local com materiais e elementos diferentes (ABBUD, 2006).

Figura 1: Plano do projeto paisagístico.

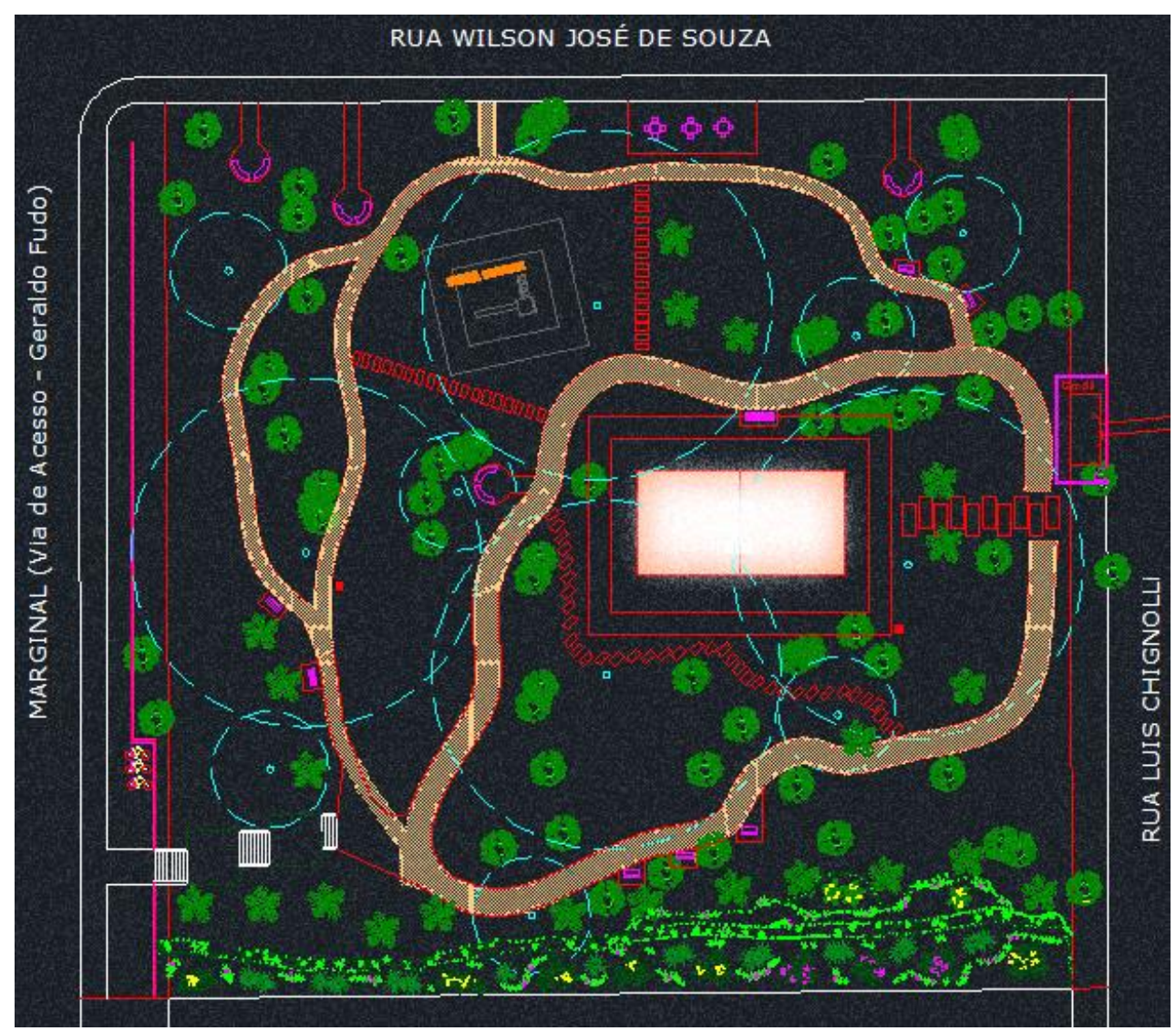

Fonte: Diretoria de Planejamento Obras e Serviços (Prefeitura Municipal de Junqueirópolis), 2014. Autor do Projeto: Arquiteta Elaine Cristina Barboza e Colaboradores: Desenhista Técnico Oswaldo Kashiura. 
Procurando manter as árvores de grande porte no local e outros elementos já existentes no próprio local, foi possível enriquecer o projeto dando a elas mais peso visual e ressaltando sua importância com os mobiliários e equipamentos: bancos e mesas, campo de areia, luminárias de duas pétalas, luminárias decorativas, torneiras para jardinagem, bebedouro, escada e bicicletario. Quanto aos pisos, considerando a importância visual, mas principalmente atentando-se para o escoamento das águas pluviais, traçaramse caminhos em função do terreno, com uma sinuosidade que acabou ainda mais marcante durante a execução da mesma e adaptações de forma inusitada diante da natureza topográfica local; e os cuidados com a manutenção da permeabilidade do solo - além do concreto de calçamento utilizaram-se como cobertura do solo, pré-moldados em concreto articulado e concreto vazado; bem como peças de concreto moldadas em canteiro de diferentes tamanhos para locais específicos do projeto. Foi previsto o plantio de vinte e cinco árvores, destacando Ipês-rosa, e Flamboyants amarelos, paralelo à manutenção dos Bambus entouceirados junto ao muro de divisa, que trouxe continuidade ao verde de Grama-Batatais do talude.

\section{RESULTADOS}

A obra teve início em meados de junho de 2014, tendo sido totalmente concluída em janeiro de 2015, após algumas modificações no sistema de iluminação da área. Todos os vazios projetados, após serem preenchidos com grama e arbustos compõe um conjunto que de fato, atingirá seu ápice após o crescimento das espécies plantadas. Espera-se que dentro de dez anos, o impacto da vegetação de grande porte terá significado maior quanto a sombreamento e contribuição para conforto térmico, como resfriamento passivo das ruas, variação da temperatura do ar e geometria do recinto urbano (MASCARÓ, 2010).

Destacamos a seguir a distribuição dos elementos do projeto descritos acima e o estado de manutenção registrado em setembro deste ano (Quadro 3). 
Quadro 3: Implantação e equipamentos

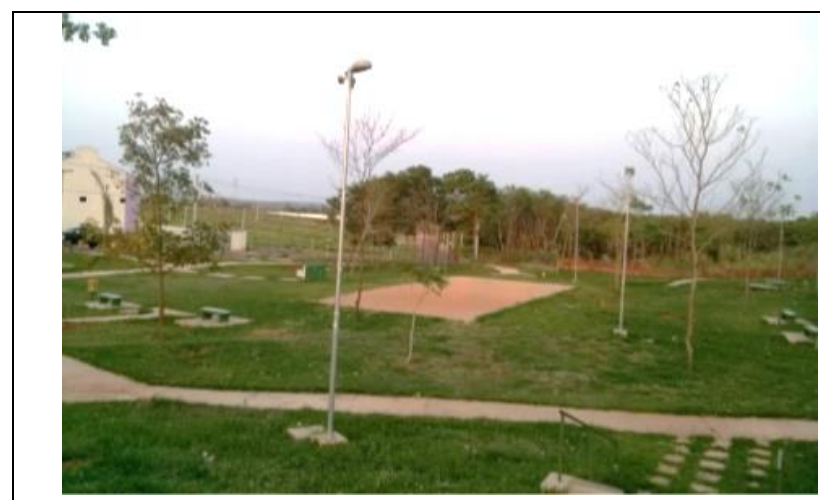

3. A - Panorâmica (campo de areia ao centro).

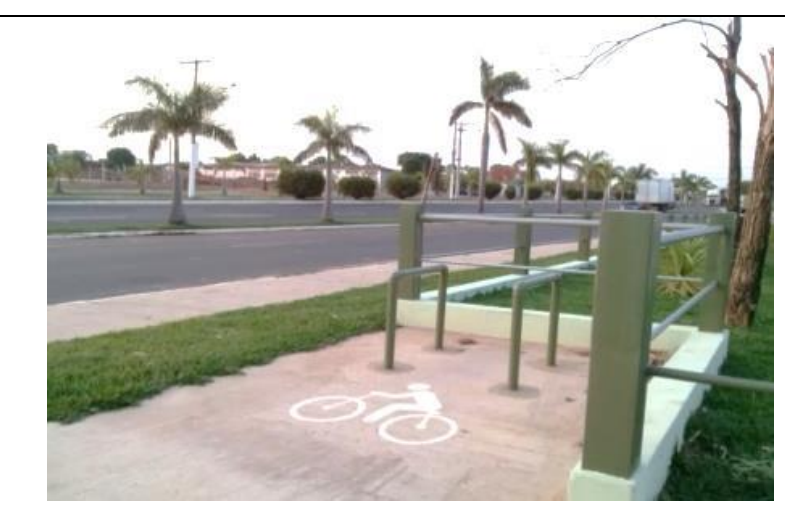

3. C - Bicicletario e mureta de proteção.

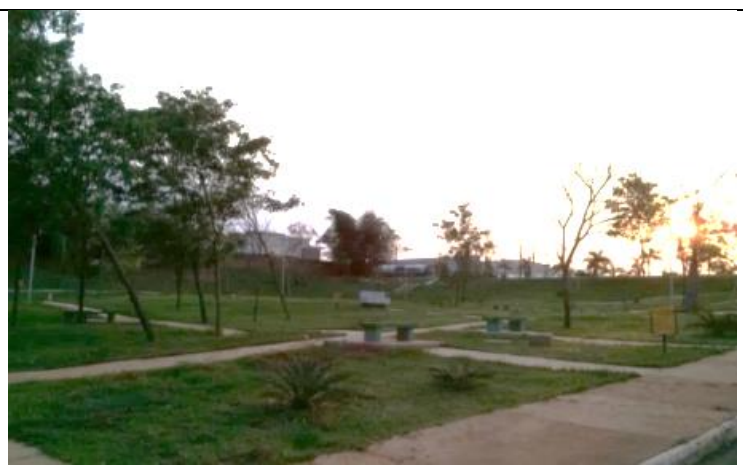

3. E-Plantio de arbustos (vegetação de médio porte).

Fonte: AUTORES, 2015.

Quanto a localização da praça, o desenvolvimento da cidade nesta região levará a ocupação em breve da porção norte da cidade, haja visto a implantação de loteamentos na proximidade e ainda no ano de 2014, inclusive com as áreas verdes dispostas na continuidade desta praça - parte da região é
3. B - Escada como acesso principal a praça.

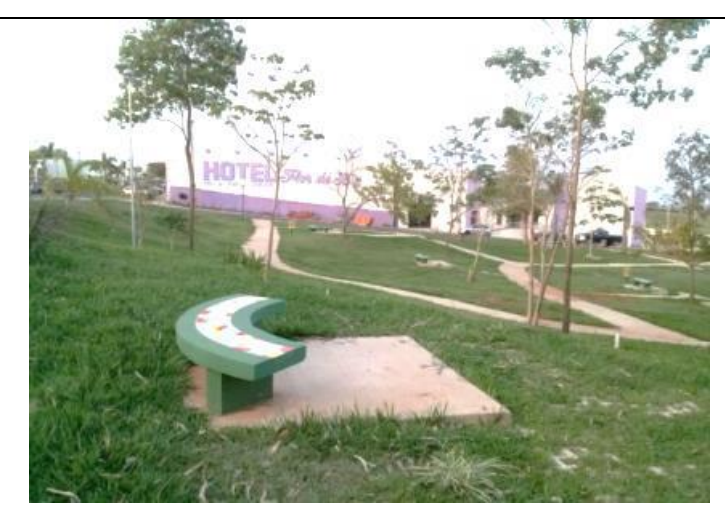

3. D - Bancos sobre piso de bloco vazado para preenchimento com grama.

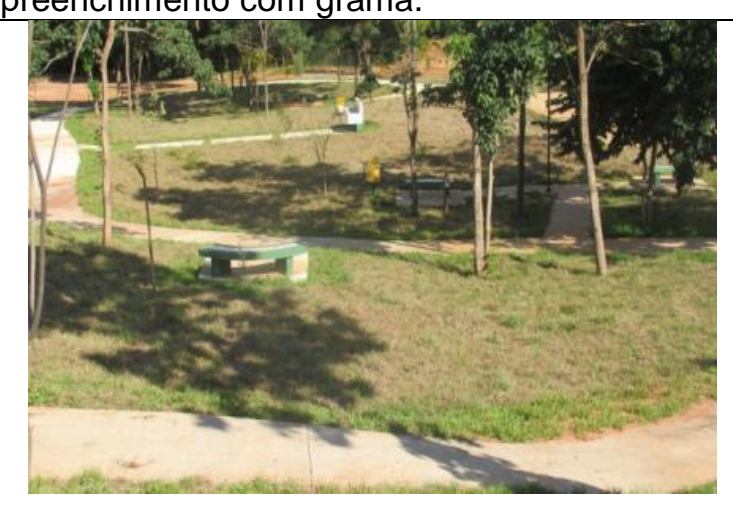

3. F - Bebedouro, lixeiras e áreas sombreadas.
FOnTE:AUTORES, 2015. 
caracterizada pela presença de áreas de preservação permanente (APPs) que conforme leis estaduais deverão ser mantidas para equilíbrio ambiental - no entanto, como fora observado por Gouvêa (2002), seria necessário manter o parcelamento solo destas áreas de preservação, ainda afastados por $60 \mathrm{~m}$ para permitir a penetração de brisas nos núcleos urbanos nos climas tropicais quentes.

Por outro lado, ressaltamos a importância do manejo da vegetação nas áreas urbanas, demonstrada pela manutenção dos valores mais altos da densidade de vapor em relação às superfícies impermeáveis; uma vez que a presença de vegetação é atuante em função da evapotranspiração, resultando em maiores fluxos convectivos através do calor latente $\left(Q_{E}\right)$ e valores mais baixos de $\beta$ (BARBOZA et al., 2013) . No entanto, o fluxo $Q_{E}$ pode também se exaurir por estresse hídrico nos espaços verdes, e, como ocorre sobre superfícies impermeáveis, o valor de $\beta$ pode aumentar no fim do dia. É o que parece indicar o padrão $C_{1}$ no Quadro 1 , em comparação aos padrões $C_{4}$ ou $C_{5}$. Desta constatação emerge a suspeita de que uma cobertura mista, mesmo com alguma redução do espaço verde e alguma concessão às superfícies impermeáveis, seria mais eficiente em manter o fluxo $Q_{\mathrm{E}}$.

As políticas públicas de desenvolvimento, principalmente municipais, necessitam contribuir na criação de áreas livre e de lazer urbano; e por sua vez, tais projetos devem integrar a vegetação arbórea e arbustiva com os efeitos de teto, túneis e arcadas com a finalidade de dar escala humana e vedação aos elementos da paisagem (Moretti e Nishihata, 2006 apud Bueno, 2008).

Conforme Rolnik (2000),

É preciso implementar uma política de investimento muito clara na retomada da qualidade do espaço da cidade, na retomada da sua multifuncionalidade e beleza, na retomada da ideia de uma cidade que conecta usos, funções e pessoas diferentes, em segurança. Esse modelo não só é urgente para quem defende uma posição mais democrática de utilização do espaço público, da vida pública, mas também porque é mais sustentável (ROLNIK, 2000 p.3). 


\section{CONCLUSÃO}

A sustentabilidade das cidades brasileiras é uma necessidade dos núcleos urbanos brasileiros, mas, paradoxalmente, o discurso que a reivindica não fornece as bases científicas necessárias para a sua concretização.

Nas pesquisas realizadas a vegetação se mostrou muito eficiente seja pela melhoria térmica, seja através da atenuação visual da paisagem urbana, ou mesmo como indutora do encontro de pessoas. Porém, por si só, ela perde esta eficiência. O contraste marcante entre as categorias C1 e C5 no Quadro 1 ressalta a importância da vegetação ser mesclada à exaustão com a diversidade de si-própria e das superfícies antrópicas, quantas quer possam ser concebidas.

Aquém disto, a vegetação ainda mantém seu aspecto agregador e multifuncional: cabem às ruas, as praças e parques, aos jardins das casas e atinge diferentes gerações - a sombra que se desfruta na Praça do Distrito Industrial I de Junqueirópolis (SP), foi plantada há pelo menos uma década. A dinamização do acesso ao lazer através do espaço público pode contribuir inclusive para a educação ambiental, pois instiga de diferentes maneiras o contato com a generosidade da natureza.

Neste trabalho levamos em consideração aspectos diretamente relacionados com a aplicação dos resultados anteriormente estabelecidos, para a metodologia de criação de projeto e intervenção urbana, evidenciando a importância da vegetação e, sobretudo sua diversidade florística permeada pelos equipamentos projetados nos espaços de lazer, o que de fato pode quiçá garantir a apregoada qualidade ambiental aos nossos espaços livres urbanos.

\section{REFERÊNCIAS BIBLIOGRÁFICAS}

ABBUD, B. Criando Paisagens:

guia de trabalho em arquitetura paisagística. São Paulo Ed. Senac, 2006. 


\section{Periódica Eletrônica

BARBOZA, E. C.; MACHADO, A. J.; FRANCHINI, A. A.. Estimativa do balanço de energia na superfície em cidades do Oeste Paulista, Brasil. In: ENCONTRO LATINOAMERICANO DE CONFORTO NO AMBIENTE CONSTRUÍDO, 8., Brasília, 2013. Anais do Congresso, Brasília: ANTAC, 2013. p. 251-257.

BARBOZA, E. C.; MACHADO, A. J. Bowen ratio in Western São Paulo State, Brazil.In: INTERNATIONAL CONFERENCE ON BUILDING, ARCHITECTURE AND URBANISM, 17, Barcelona, 2015. Barcelona: WASET, 2015. World Academy of Science, Engineering and Technology Vol:9 2015-09-03 p. 294-297.

BERNARDIN, P. O Império Ecológico - ou a subversão da ecologia pelo globalismo. Tradução: Felipe Lesage e Diogo Chiuso. 1aㅡ ed., Vide Editorial, 2015.

BUENO, L. M. M. Reflexões sobre o futuro da sustentabilidade urbana com base em um enfoque socioambiental. Cadernos metrópole, vol. 19, p. 99-121, 2008.

GOUVÊA, L. A. C. Biocidade: conceitos e critérios para um desenho ambiental urbano, em localidades de clima tropical de planalto. São Paulo: Nobel, 2002.

GRIMMOND, C. S. B. and OKE, T.R. An evapotranspiration-interception model for urban areas, Water Resources Research, vol. 27, 1739-1755, 1991.

INSTITUTO BRASILEIRO DE GEOGRAFIA E ESTATÍSTICA - IBGE, Cidades@. Disponível em: <http://www.cidades.ibge.gov.br/ > Acesso em 08 de outubro de 2015.

MACEDO, S. S. Paisagismo brasileiro na virada do século: 1990-2010. São Paulo e Campinas: EDUSP/ Editora UNICAMP, 2012. 344 p.

MAGNOLI, M. M. O parque no desenho urbano. Paisagem Ambiente: ensaios - n. 21, São Paulo, 2006, p. 199-213.

MASCARÓ, L. e MASCARÓ, J. Vegetação urbana. Porto Alegre: Mais Quatro: UFRGS, 2010.

OKE, T. R. Boundary Layer Climates.2 $2^{\mathrm{a}}$ ed., London, Routledge, 1987.

ROMERO, M. A. B. Princípios Bioclimáticos para o desenho urbano. São Paulo, Pro Editores, 2000.

ROLNIK, R.. O lazer humaniza o espaço urbano. In: SESC SP. (Org.). Lazer numa sociedade globalizada. São Paulo: SESC São Paulo/World Leisure, 2000. Disponível em:

<http://raquelrolnik.files.wordpress.com/2009/08/lazerhumanizaespacourbano.pdf > Acesso em 10 de março de 2013. 